\title{
Chylous ascites as a late complication of one anastomosis gastric bypass-minigastric bypass: case report
}

\author{
Ibrahim Abu Shakra ${ }^{1 \dagger}$, Maxim Bez ${ }^{1,2+}$, Amitai Bickel ${ }^{1,3}$, Walid Kassis ${ }^{1}$, Samer Ganam¹, Fahed Merei ${ }^{1}$, Nour Karra ${ }^{1}$,
} Khatib Kamal ${ }^{1}$, Doron Fischer ${ }^{4}$ and Eli Kakiashvili ${ }^{1,3^{*}}$

\begin{abstract}
Background: One anastomosis gastric bypass- minigastric bypass (OAGB-MGB) is an emerging bariatric surgery that is being endorsed by surgeons worldwide. Internal herniation is a rare and dreaded complication after malabsorptive bariatric procedures, which necessitates early diagnosis and intervention.

Case presentation: We describe a 29-year-old male with chylous ascites caused by an internal hernia 8 months following laparoscopic one anastomosis gastric bypass. An abdominal CT showed enlargement of lymph nodes at the mesentery, with a moderate amount of liquid in the abdomen and pelvis. An emergent exploratory laparoscopic surgery demonstrated an internal hernia at the Petersen's space with a moderate quantity of chylous ascites. The patient made an uneventful recovery after surgery.

Conclusions: Internal herniation can occur after OAGB-MGB and in extremely rare cases lead to chylous ascites. To our knowledge, this is the first reported case of chylous ascites following one anastomosis gastric bypass.
\end{abstract}

Keywords: Case report, Bariatric surgery, Gastric bypass, Internal hernia, Chylous ascites

\section{Background}

One-anastomosis gastric bypass- minigastric bypass (OAGBMGB) is an emerging bariatric surgery technique currently endorsed by surgeons worldwide [1, 2]. Similar to Roux-en-Y gastric bypass (RYGB), OAGB-MGB is both a restrictive and malabsorptive operation that involves the creation of a single anastomosis. OAGB-MGB is done by dividing the stomach between the antrum and body on the lesser curvature. This creates a pouch that is anastomosed to a small bowel loop as an antecolic and antegastric loop gastrojejunostomy. OAGBMGB is considered a simpler and faster procedure compared with RYGB, while having similar post-operative weight loss rates $[3,4]$. A recent meta-analysis reported higher excess

\footnotetext{
* Correspondence: elik@gmc.gov.il

${ }^{\dagger}$ Ibrahim Abu Shakra and Maxim Bez contributed equally to this work.

${ }^{1}$ Department of Surgery A, Galilee Medical Center, Nahariya, Israel

${ }^{3}$ Faculty of Medicine in the Galilee, Bar-Ilan University, Safed, Israel

Full list of author information is available at the end of the article
}

weight loss achievable with OAGB-MGB at 5 years followup [5].

Early complication rates of OAGB-MGB range from 0.5 to $3.1 \%$ [3]. Early major complications requiring reoperation were reported in $1.3 \%$ of patients. Late complications, which occur in $10 \%$ of patients, include stomal stenosis, marginal ulcers, protein calorie malnutrition, bile reflux, and internal herniation of the small bowel which leads to bowel obstruction. In extremely rare cases internal hernia can cause chylous ascites following RYGB [6]. This, however, has not been observed in OAGB-MGB.

\section{Case presentation}

We report a 29-year-old male, otherwise healthy, who presented to our emergency department, complaining of severe diffuse abdominal pain that had developed over

(C) The Author(s). 2020 Open Access This article is licensed under a Creative Commons Attribution 4.0 International License, which permits use, sharing, adaptation, distribution and reproduction in any medium or format, as long as you give appropriate credit to the original author(s) and the source, provide a link to the Creative Commons licence, and indicate if changes were made. The images or other third party material in this article are included in the article's Creative Commons licence, unless indicated otherwise in a credit line to the material. If material is not included in the article's Creative Commons licence and your intended use is not permitted by statutory regulation or exceeds the permitted use, you will need to obtain permission directly from the copyright holder. To view a copy of this licence, visit http://creativecommons.org/licenses/by/4.0/ The Creative Commons Public Domain Dedication waiver (http://creativecommons.org/publicdomain/zero/1.0/) applies to the data made available in this article, unless otherwise stated in a credit line to the data. 


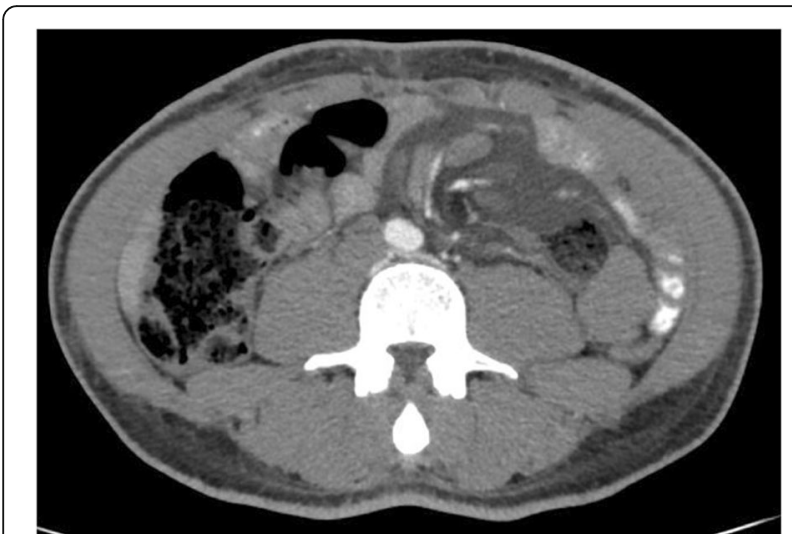

Fig. 1 Abdominal computed tomography with intravenous contrast showing diffuse enlargement of mesenteric lymph nodes

the last $24 \mathrm{~h}$, and had become progressively worse with time. The patient did not report any constipation, diarrhea, or distention despite having nausea and vomiting. He had undergone laparoscopic OAGB-MGB in a different medical center 8 months prior to his admission (Body mass index (BMI) prior to the surgery: $42 \mathrm{~kg} / \mathrm{m}^{2}$; weight loss $53 \mathrm{~kg}$ ). On physical examination, the patient's vital signs were within normal range. The patient had no fever. Abdominal auscultation revealed normal bowel sounds. Upon abdominal palpation, the patient complained of diffuse tenderness. His lab results, including lactate, amylase and lipase were all within normal limits.

A computed tomography scan of the abdomen and the pelvis following oral and intravenous contrast administration demonstrated no evidence of intestinal obstruction or free air. Enlarged lymph nodes at the root of the mesentery were observed, with a moderate amount of free liquid of unknown origin in the abdomen and pelvis (Fig. 1). The above finding led to the decision to perform an emergent exploratory laparoscopic surgery, which demonstrated a moderate quantity of chylous ascites. Further exploration revealed the presence of an internal hernia that involved the alimentary loop, which was misplaced within the Petersen's space with engorged lymphatic vessels within the mesenteric root (Fig. 2). Several peritoneal lavages were performed, the internal hernia was reduced and the opening was narrowed. A sample of the ascites fluid demonstrated a triglyceride level of $159 \mathrm{mg} / \mathrm{dl}$. The postoperative course was satisfactory and the patient was discharged without symptoms at 4 days postoperative.

\section{Discussion and conclusions}

Parallel to dramatic increases worldwide in obesity prevalence, surgical procedures aimed to induce and maintain weight loss have increased considerably over recent years. Both RYGB and OAGB-MGB are common, well-tolerated and effective operations for morbid obesity. Both surgeries carry similar rates of complications and reoperations, with leaks and hemorrhages being the most common due to the gastrointestinal anastomoses [5].

An internal herniation is a dangerous late complication that may occur after both RYGB and OAGB-MGB procedures (although much less commonly) and is characterized by symptoms of abdominal obstruction [7]. Clinicians need to be aware of such complication as delayed diagnosis may result in small bowel ischemia and death. The most common site for internal hernia to occur is the Petersen's space. The incidence of an internal hernia and bowel obstruction was found to be higher following RYGB than either OAGB-MGB or sleeve gastrectomy [7]. According to a consensus statement on OAGB-MGB, $71 \%$ of the experts agreed that routine closure of the Petersen's space should not be done routinely [8]. However, due to the increased number of reports of Petersen's hernia after OAGB-MGB, opinions of some experts have started to shift [9].

Chylous ascites in a bariatric surgery setting generally occurs by a loop passing through the Petersen's defect, which causes direct compression of the mesenteric vessels and fluid extravasation. In previous case reports of patients with chylous ascites following RYGB, the complication was resolved by the release of the internal hernia compressing the mesenteric lymphatic vessels [6]. Similar to these reports, the cause of chylous ascites in

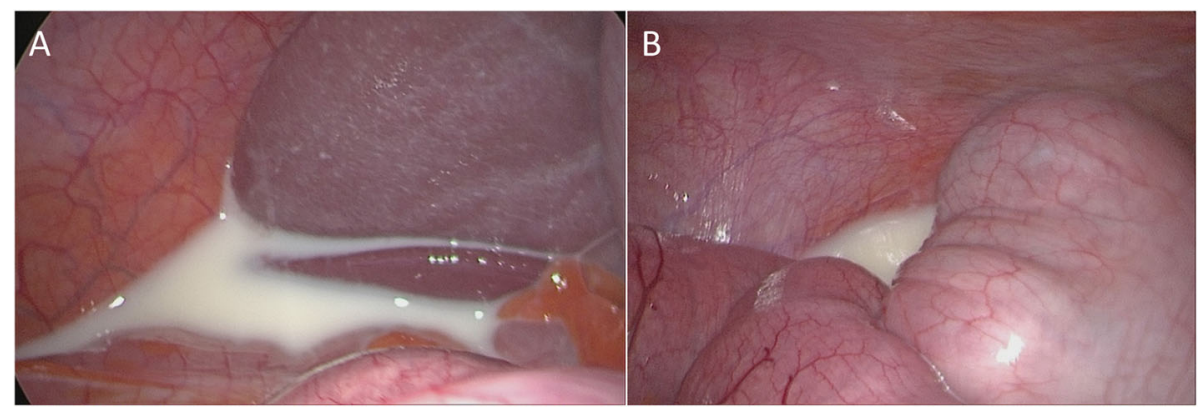

Fig. 2 Laparoscopic aspect. Chylous ascites can be seen in the peritoneum (a) and in the pelvic cavity (b) due to a lymphatic leak 
our patient was the direct obstruction of the lymphatic vessels, secondary to an internal hernia through the mesenteric defect at the Petersen's space. Therefore, the release of the internal hernia causing the obstruction resulted in the resolution of the chylous ascites.

Closure of the mesenteric defect at the time of the primary surgery has been shown to reduce the occurrence of internal hernia following RYGB procedures [10]. Although the closure increases risk of early small bowel obstruction caused by kinking of the jejunojejunostomy or damage to the mesenteric vessels, this is unlikely to occur in OAGBMGB, due to the absence of a jejunojejunostomy. Since internal herniation is a potentially serious complication, the inclusion of the routine closure of the mesenteric defect in OAGB procedures warrants evaluation.

In conclusion, internal hernia is a dangerous complication following OAGB, which in extremely rare cases can lead to chylous ascites. Surgical intervention is required to release the hernia and relieve the compression of the lymphatic vessels. Closure of the potential spaces that can lead to internal herniation should be evaluated in OAGB.

\section{Abbreviations}

OAGB-MGB: One anastomosis gastric bypass- minigastric bypass; RYGB: Rouxen-Y gastric bypass; BMI: Body mass index

\section{Acknowledgements}

Not applicable.

\section{Authors' contributions}

$I A S, M B, A B$ and $W K$ are the operating surgeons and participated in the preparation of the manuscript. IAS, MB and DF participated in patient data collection and image revisions. SG, FM, KK and NK performed literature review and were involved in patient care. IAS, MB and EK wrote the manuscript. All authors read and approved the final case report.

\section{Funding}

None.

Availability of data and materials

Not applicable.

Ethics approval and consent to participate

Not applicable.

\section{Consent for publication}

Written informed consent was obtained from the patient for publication of this Case report and any accompanying images. A copy of the written consent is available for review by the Editor of this journal.

\section{Competing interests}

The authors declare that they have no competing interests.

\section{Author details}

${ }^{1}$ Department of Surgery A, Galilee Medical Center, Nahariya, Israel. ${ }^{2}$ Medical Corps, Israel Defense Forces, Ramat Gan, Israel. ${ }^{3}$ Faculty of Medicine in the Galilee, Bar-llan University, Safed, Israel. ${ }^{4}$ Department of Radiology, Galilee Medical Center, Nahariya, Israel.
Received: 19 November 2019 Accepted: 28 April 2020

Published online: 06 May 2020

\section{References}

1. Carbajo M, García-Caballero M, Toledano M, Osorio D, García-Lanza C, Carmona JA. One-anastomosis gastric bypass by laparoscopy: results of the first 209 patients. Obes Surg. 2005;15(3):398-404.

2. Rutledge R. The mini-gastric bypass: experience with the first 1,274 cases. In: Obesity Surgery; 2001.

3. Robert M, Espalieu P, Pelascini E, Caiazzo R, Sterkers A, Khamphommala L, et al. Efficacy and safety of one anastomosis gastric bypass versus roux-en-Y gastric bypass for obesity (YOMEGA): a multicentre, randomised, open-label, non-inferiority trial. Lancet. 2019;393(10178):1299-309.

4. Ruiz-Tovar J, Carbajo MA, Jimenez JM, Castro MJ, Gonzalez G, Ortiz-deSolorzano J, et al. Long-term follow-up after sleeve gastrectomy versus roux-en-Y gastric bypass versus one-anastomosis gastric bypass: a prospective randomized comparative study of weight loss and remission of comorbidities. Surg Endosc. 2019;33(2):401-10.

5. Magouliotis DE, Tasiopoulou VS, Tzovaras G. One anastomosis gastric bypass versus roux-en-Y gastric bypass for morbid obesity: an updated metaanalysis. Obes Surg. 2019;29(9):2721-30.

6. Zaidan LR, Ahmed EK, Halimeh B, Radwan Y, Terro K. Long standing biliary colic masking chylous ascites in laparoscopic roux-en-Y gastric bypass; A case report. BMC Surg. 2018;18:43.

7. Musella M, Susa A, Manno E, De Luca M, Greco F, Raffaelli M, et al. Complications following the mini/one anastomosis gastric bypass (MGB/ OAGB): a multi-institutional survey on 2678 patients with a mid-term (5 years) follow-up. Obes Surg. 2017;27(11):2956-67.

8. Ramos AC, Chevallier JM, Mahawar K, Brown W, Kow L, White KP, et al. IFSO (International Federation for Surgery of obesity and metabolic disorders) consensus conference statement on one-anastomosis gastric bypass (OAGBMGB): results of a modified Delphi study. Obes Surg. 2020;30(5):1625-34.

9. Mahawar KK. Petersen's hernia may be commoner after OAGB/MGB than previously reported. Obes Surg. 2018;28(1):257-8.

10. Stenberg E, Szabo E, Ågren G, Ottosson J, Marsk R, Lönroth H, et al. Closure of mesenteric defects in laparoscopic gastric bypass: a multicentre, randomised, parallel, open-label trial. Lancet. 2016;387(10026):1397-404.

\section{Publisher's Note}

Springer Nature remains neutral with regard to jurisdictional claims in published maps and institutional affiliations.
Ready to submit your research? Choose BMC and benefit from:
- fast, convenient online submission
- thorough peer review by experienced researchers in your field
- rapid publication on acceptance
- support for research data, including large and complex data types
- gold Open Access which fosters wider collaboration and increased citations
- maximum visibility for your research: over $100 \mathrm{M}$ website views per year
At BMC, research is always in progress.
Learn more biomedcentral.com/submission 